Rev. Latinoam. Psicopat. Fund., São Paulo, 20(2), 399-402, jun. 2017

http://dx.doi.org/10.1590/1415-4714.2017v20n2p399-12

Rumo a uma nova epistemologia da psiquiatria

German E. Berrios

São Paulo: Escuta, 2015, 296 págs.

\title{
Epistemologia, história e a linguagem da psicopatologia
}

Rafaela Zorzanelli*1

Claudio E. M. Banzato*2

Em uma disciplina conectada conceitualmente com o passado de forma profunda, como é o caso da psiquiatria, a conjugação das análises históricas e epistemológicas pode ser bastante iluminadora e é sempre muito bem-vinda. E essa é precisamente a marca da trajetória intelectual de German E. Berrios, psiquiatra peruano radicado na Inglaterra e um dos principais historiadores da psiquiatria de nosso tempo (senão o principal), além de importante pensador crítico e propositivo da disciplina. O livro ora apresentado, Rumo a uma nova epistemologia da psiquiatria, lançado no Brasil em 2015 pela editora Escuta e cujo texto original em inglês datado de 2011 ainda não foi publicado, fornece uma excelente amostra do longo histórico de contribuições do autor na área de epistemologia, com o exame cuidadoso da natureza dos objetos e

\footnotetext{
*1 Universidade do Estado do Rio de Janeiro - UERJ (Rio de Janeiro, RJ. Br)

*2 Universidade Estadual de Campinas - Unicamp (Campinas, SP, Br).
} 


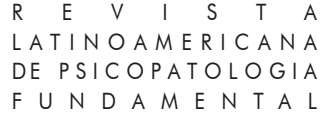

dos conceitos psiquiátricos. Reunindo adaptações de trabalhos desenvolvidos nas últimas décadas (e já publicados em inglês na forma de artigos e capítulos de livro), o livro está estruturado em quatro partes: I. Filosofia e epistemologia da psiquiatria; II. A linguagem da psiquiatria; III. Objetos da psiquiatria e IV. Dados psiquiátricos.

No livro, há uma clara opção pela exposição da visão coerente e de conjunto de uma escola de pensamento, a chamada escola de Cambridge, criada e liderada por Berrios, que possui em estilo de pensamento próprio, combinando de forma particularmente frutífera e consequente a história e a epistemologia da disciplina. Realiza-se uma historicização da psiquiatria não apenas em sua trajetória como campo de saber, mas naquilo que dela se toma como dado, como por exemplo seus conceitos e, ao mesmo tempo, não abre mão da construção radical de uma epistemologia da psiquiatria que garanta seu desenvolvimento por meio da crítica aos seus pressupostos, já que esse desenvolvimento não pode ser almejado nem garantido somente pelas pesquisas neurobiológicas. Esse ponto fica bastante claro quando o autor advoga que os sintomas mentais não podem ser explicados por estruturas neurobiológicas, mas apenas pelo envelope semântico que lhes dá um valor particular.

$\mathrm{Na}$ leitura do livro, fica evidente a centralidade da ideia de que os transtornos mentais, para a escola de Cambridge, constituem não objetos naturais, mas objetos híbridos, com componentes originários dos mundos natural e social, articulados da seguinte maneira: "são as ciências humanas que configuram o objeto da investigação psiquiátrica. Uma vez que tenha sido concluído, as ciências naturais se movem para procurar as ligações entre essas configurações semânticas e o corpo" (p. 28). Disso decorre outra afirmação crucial reiterada ao longo do livro e que possui grande consequência: a de que é necessária uma recalibração periódica da linguagem psicopatológica da psiquiatria, ou seja, uma combinação do poder de resolução da linguagem de descrição com os objetos investigados. Isso contraria a noção prevalente de que o trabalho de reconhecimento, identificação e descrição dos sintomas foi finalizado há muito tempo e de que resta apenas a busca pelas bases neurobiológicas subjacentes a tais manifestações.

Sua defesa de que a psiquiatria lida com constructos é um dos pontos que transpassa o livro, nos diferentes capítulos, confirmando sua visão de que esse é um conceito útil para informar nossa visão a respeito do campo. Em suas palavras, "muitos 'transtornos mentais' são apenas grupos de queixas ligados pela mesma episteme, com um baixo índice ontológico e trans-epistêmico, ou 


\section{RESENHAS BIBLIOGRÁFICAS}

seja, não são tipos naturais e, portanto, não sobrevivem bem a uma translocação de um período histórico para o próximo" (p. 113), justificando assim a defesa de que a análise dos sintomas mentais como unidades neurobiológicas e epistemológicas - e não dos transtornos - poderia ser mais útil.

Em oposição a esse estado de coisas, e de forma condizente com a perspectiva historicizante adotada, a escola de Cambridge propõe um modelo original, sofisticado e integrativo da formação de sintomas mentais, em que estes são entendidos como co-construcões hermenêuticas que ocorrem num espaço intersubjetivo. Outra proposta central da escola de Cambridge é resumida pela ideia de "auditagem conceitual da psiquiatria", ou seja, que seus conceitos e práticas sejam, com frequência, alvo de inspeção e vistoria. A recomendação de nunca deixar permanecer parado um conceito ou um modo de fazer, mas torná-lo permanentemente alvo de monitoramento, faz com que as análises epistemológicas e históricas ocupem lugares de destaque. Tal modelo funciona como uma advertência contra o realismo ingênuo e permite o desenvolvimento de investigações empíricas que fazem mais justiça à complexidade do objeto psiquiátrico.

Ressaltada a alta qualidade do livro, cumpre apontar alguns aspectos críticos. Não fica claro, na edição em questão, que estamos diante de uma obra que ainda não foi publicada como livro em sua língua original (inglês) e que compila adaptações de textos escritos em diferentes momentos. Isso poderia ficar mais explícito, o que ajudaria a situar melhor o valor individual de cada contribuição específica. Embora a falta de referências bibliográficas seja intencional (com o intuito de proporcionar ganho de fluidez na leitura), isso talvez comprometa parcialmente a viabilidade do livro como obra de referência em que ele de fato se constituirá, devendo ser consultada por uma vasta gama de leitores interessados na psiquiatria. Por fim, se a exposição coerente e a visão de conjunto de uma escola de pensamento são bem-sucedidas, quase não há diálogo com a prolífica literatura recente da filosofia da psiquiatria (o que não impede que existam em certas passagens algumas desqualificações genéricas, isto é, sem que se mencionem os nomes dos autores criticados). Nada disso, contudo, diminui o mérito do livro, que temos a satisfação de recomendar por vários motivos: pela lucidez epistemológica que exibe ao formular perguntas fundamentais, pelas valiosas contribuições substanciais (como o exame das bases conceituais da psicopatologia, de sua linguagem e a proposição de um modelo original de formação de sintomas, para citar apenas duas) e pelo ótimo exemplo de retroalimentação entre psiquiatria e filosofia, além do incentivo à pesquisa conceitual de qualidade. 


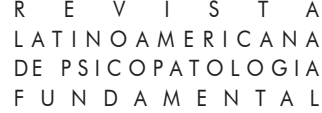

Citação/Citation: Zorzanelli, R., \& Banzato, C. E. M. (2017, junho). Epistemologia, história e a linguagem da psicopatologia. Resenha do livro Rumo a uma nova epistemologia da psiquiatria. Revista Latinoamericana de Psicopatologia Fundamental, 20(2), 399-402. http://dx.doi.org/10.1590/1415-4714.2017v20n2p399-12

Editores do artigo/Editors: Profa. Dra. Sonia Leite

Recebido/Received: 15.4.2016 / 4.15.2016 Aceito/Accepted: 8.6.2016 / 6.8.2016

Copyright: (C 2009 Associação Universitária de Pesquisa em Psicopatologia Fundamental/ University Association for Research in Fundamental Psychopathology. Este é um artigo de livre acesso, que permite uso irrestrito, distribuição e reprodução em qualquer meio, desde que o autor e a fonte sejam citados / This is an open-access article, which permits unrestricted use, distribution, and reproduction in any medium, provided the original authors and sources are credited.

\section{RAFAela Zorzanelli}

Psicóloga; Doutora em Saúde Coletiva; Professora Adjunta do Instituto de Medicina Social da Universidade do Estado do Rio de Janeiro - UERJ (Rio de Janeiro, RJ, Br).

Rua São Francisco Xavier, 524, Pavilhão João Lyra Filho, $7^{\circ}$ andar / blocos D e E, e $6^{\circ}$ andar / bloco E - Maracanã

20550-013 Rio de Janeiro, RJ, Br.

rtzorzanelli@yahoo.com.br

\section{Claudio E. M. Banzato}

Psiquiatra; Doutor em Filosofia; Professor Titular do Departamento de Psicologia Médica e Psiquiatria da Faculdade de Ciências Médicas da Universidade Estadual de Campinas Unicamp (Campinas, SP, Br).

Rua Tessália Vieira de Camargo, 126 - Cidade Universitária

13.083-887 Campinas, SP, Br.

cbanzato@fcm.unicamp.br

This is an open-access article, which permits unrestricted use, distribution, and reproduction in any medium for non-commercial purposes provided the original authors and sources are credited. 